Classification

Physics Abstracts

$07.80-68.35-82.80$

\title{
EPMA Sputter Depth Profiling: A New Technique for Quantitative in-Depth Analysis of Layered Structures
}

\author{
Peter Karduck $\left({ }^{1, *}\right)$ and Alexander von Richthofen $\left({ }^{2}\right)$ \\ ( $\left.{ }^{1}\right)$ Gemeinschaftslabor für Electronenmikroskopie, GFE, Rheinisch-Westfälische Technische \\ Hochschule Aachen, 52056 Aachen, Germany \\ $\left({ }^{2}\right)$ Lehrstuhl für' Theoretische Hüttenkunde, Rheinisch-Westfälische Technische Hochschule Aachen, \\ 52056 Aachen, Germany
}

(Received September 1; accepted September 29, 1995)

\begin{abstract}
The remarkable features of modern EPMA techniques are high sensitivity for very small coverages of thin films on substrates $\left(10^{14} \mathrm{~cm}^{-2}\right)$ and a reliable quantitative determination of elemental compositions. The present work makes use of these features and combines them with ion sputtering of the sample surface to extend the capability of EPMA to real in-depth analysis in the submicron range. The general theoretical background of this EPMA-sputter-depth profiling is worked out and on the basis of a Monte-Carlo simulation model a technique was developed to reconstruct surface near depth profiles by a multiple thin film model. As a result, this new approach is able to determine depth profiles quantitatively with regard to both composition and the real depth coordinate in terms of mass coverage. After having been verified at an artificial layer system of different Ti-Al-N-O-compounds the new technique was used to study oxide scales which were grown on technical hardcoatings of the type $\mathrm{Ti}_{1-x} \mathrm{Al}_{x} \mathrm{~N}$ with different fractions $x$. Despite the roughness of the oxide scales and although the structure of different oxide types was interlocked the variation of the elemental composition with depth could be worked out quantitatively with a relative accuracy of $10 \%$. Additionally a reasonable evaluation of the depth coordinate in mass coverage could be attained, the results of which could be assessed by SEM imaging of the scales in fractured samples.
\end{abstract}

\section{Introduction}

Electron probe microanalysis (EPMA) combined with wavelength dispersive X-ray spectrometers (WDS) is a very sensitive tool to detect small coverages of a chemical element on materials surfaces. With instruments commercially available the detectability ranges down to $10^{14}$ atoms per $\mathrm{cm}^{2}$ as long as the particular element is not present in the substrate [1-3]. The coverage of these layers, as well as their composition, can be quantified from measured and calibrated characteristic $\mathrm{X}$-ray intensities by application of appropriate matrix correction methods developed particularly

(*) Author to whom correspondence should be sent. 
for the quantification of single or/and multiple layer-substrate systems. For more than ten years these techniques have been applied as routine to quantitative thin film analysis [4-8]. All EPMAtechniques presuppose that the single layers exhibit no compositional inhomogeneities over their depth. But even if this were the case, EPMA could resolve such depth profiles under certain limited circumstances and with investment of great effort by applying many different electron energies to scan the center of excitation over the depth of the sample [8-11].

The idea of the present paper is to combine the two advantages of EPMA - i.e. accurate quantitative evaluation of coverages and highly sensitive detection - with a sputtering technique as it is currently applied in Auger sputter depth profiling or crater edge linescan profiling [12]. The basic assumptions are already published by von Richthofen et al. [13] and Karduck and von Richthofen [14] and are summarized in the following:

Assuming that a layer with compositional changes in depth is being deposited or grown on a substrate, one EPMA-measurement suffices to determine the average composition and total coverage of the layer without the compositional changes influencing the results significantly. After having removed a part of the layer by ion beam sputtering, the residual partial coverages of all elements of the layer can be analysed in a second measurement. From the difference between the two results measured before and after the sputtering, the composition and mass thickness of the removed part of the layer can be determined. If this process is continued until the total layer is removed the total depth profile of all elements of the layer can be compiled quantitatively. Recently this was demonstrated successfully [13]. In the present paper a further step will be made by applying the technique to technical surfaces. Indeed, the investigation of near-surface compositional changes is of importance in various fields of materials research, e.g. in coating techniques to improve mechanical, electrical, optical or magnetical properties of materials, but also in the investigation of oxidation and corrosion phenomena. An EPMA-technique for depth profiling would open the availability of depth profile analysis also to those laboratories having EPMA-WDS systems but no AES, SIMS or other surface analytical tools at their disposal.

In analogy to depth profile analysis with AES two possible techniques can be applied. In the so-called sputter-depth profiling the surface is alternately analysed by AES and sputtered by $\mathrm{Ar}^{+}$ - or other ions. This enables depth profiles to be measured at a certain location of the surface and lateral resolution to be maintained. The second technique is called crater edge linescan profiling, in which first a flat crater is sputtered to a certain depth so that the depth profile can be measured by scanning the electron beam across the edge of the crater. Of course, in this case lateral resolution is lost, and moreover, it is assumed that the sample is laterally homogeneous. The advantage of this variant is that measurements can be repeated, if necessary. In the present investigation the crater edge linescan technique is applied since up to now no microprobe analyzer has been available with an integrated ion gun. In the following, the principles of EPMA-sputter depth profiling (EPMA-SDP) are given, and the possibilities and limits of this method are demonstrated by analysing the composition of complex structured oxide scales formed on $\mathrm{Ti}_{0.74} \mathrm{Al}_{0.26} \mathrm{~N}$, $\mathrm{Ti}_{0.46} \mathrm{Al}_{0.54} \mathrm{~N}$ and $\mathrm{Ti}_{0.25} \mathrm{Al}_{0.75} \mathrm{~N}$ hardcoatings. To verify the results of the EPMA-SDP investigation the composition of the oxide scale of $\mathrm{Ti}_{0.46} \mathrm{Al}_{0.54} \mathrm{~N}$ was analysed by Auger crater edge profiling in addition.

\section{Theoretical Description of EPMA-SDP}

2.1 General Considerations. - Considering a surface - near concentration profile $n_{\mathrm{A}}(z)$ of atoms A with $n$ as the number of atoms per $\mathrm{cm}^{3}$ we can calculate the emitted X-ray intensity from 
this structure by

$$
I_{\mathrm{A}}=\text { const } \cdot \int_{0}^{\infty} \mathrm{d} z \cdot n_{\mathrm{A}}(z) \cdot K(\Gamma, z) \text { with } K(\Gamma, z)=\Phi(\Gamma, z) \cdot \exp (-\mu(z) \cdot z / \sin \Theta)
$$

The const takes solid angle, sensitivity of spectrometer and atomic constants into consideration. $K$, the Kernel of the integral, represents the analysing probe and contains the depth distribution of X-ray production $\Phi(\Gamma, z)$ and the absorption term with the $z$-depending absorption coefficient $\mu(z)$. $\Gamma$ represents the set of measuring parameters: electron energy $E_{0}$, the critical excitation energy $E_{n l}$, the angle of electron beam incidence $\vartheta$ and the take off angle of the spectrometer $\Theta$. $\mu$ depends on $z$ because the composition of the sample varies with depth according to $n_{\mathrm{A}}(z)$. $\Phi(\Gamma, z)$ depends also on the composition of the sample.

We now assume an experiment analogous to the technique of Auger sputter depth profiling, in which we alternately remove a thin layer of thickness $\mathrm{d} z^{\prime}$ from the sample by sputtering and measure the emitted X-ray intensity before each new sputtering step. This experiment results in an intensity curve as a function of the sputtered depth $z^{\prime}$ :

$$
I\left(z^{\prime}\right)=\text { const } \cdot \int_{z^{\prime}}^{\infty} \mathrm{d} z \cdot n_{\mathrm{A}}(z) \cdot K\left(\Gamma, z-z^{\prime}\right)
$$

Regarding the sputtering process as continuous, allows the first derivative of Equation (2) to be calculated with respect to the sputtered depth $z^{\prime}$ :

$$
-\frac{\partial}{\partial z^{\prime}} I=\text { const } \cdot n_{\mathrm{A}}\left(z^{\prime}\right) \cdot K(\Gamma, 0)-\text { const } \cdot \int_{z^{\prime}}^{\infty} \mathrm{d} z \cdot n_{\mathrm{A}}(z) \cdot \frac{\partial}{\partial z^{\prime}} K\left(\Gamma, z-z^{\prime}\right)
$$

This expression describes how the emitted intensity changes with the sputtered depth. The variation of emitted X-ray intensity with sputtered depth - $\mathrm{d} I$ is composed of two different contributions. The first term results from the actual surface layer of the crater with thickness $\mathrm{d} z^{\prime}$ and is proportional to the concentration of the emitting element $n_{\mathrm{A}}\left(z^{\prime}\right)$, the thickness of the removed layer $\mathrm{d} z^{\prime}$ and the surface ionization $K(\Gamma, 0)$. The product $n_{\mathrm{A}}\left(z^{\prime}\right) \cdot \mathrm{d} z^{\prime}$ is the coverage of element $\mathrm{A}$ in a layer of thickness $\mathrm{d} z^{\prime}$ in depth $z^{\prime}$. In simplified terms the second contribution can be regarded as an integral from $z^{\prime}$ to $\infty$ over the first derivative of $K\left(z-z^{\prime}\right)$ with respect to $z^{\prime}$ multiplied by the concentration profile $n_{\mathrm{A}}(z)$. Due to the large depth of integration in the range of some $100 \mathrm{~nm}$ up to $1 \mu \mathrm{m}$ the second contribution is expected to be rather insensitive to the concentration depth profiles and thus will contribute a more or less constant background - like signal, if the compositional variations take place in depth much smaller than the electron range. This is the case for high beam energies. If $E_{0}$ is below $10 \mathrm{keV}$ and if the depth, where compositional changes take place, is of the same order as the electron range, the contribution of the second term is of a more complex nature and can contribute strongly to the overall intensity variation with sputtered depth.

To illustrate the significance of the two terms in Equation (3) Figure 1 compares an X-ray depth distribution $K(\Gamma, z)$, typical for the excitation by $3 \mathrm{keV}$ - electrons, with the difference between two distributions slightly shifted against each other by $z^{\prime}=2.6 \mathrm{~nm}$. The first term in Equation (3) is represented by the sharp near-surface part of the $\Delta K$-curve which elucidates the surface sensitive part of $\partial I / \partial z^{\prime}$. The second part of the $\Delta K$-curve for $z>z^{\prime}$ indeed demonstrates that the integral term in Equation (3) must be rather insensitive to the concentration depth profile, as long as the variation of $n_{\mathrm{A}}(z)$ takes place in depths $z$ much smaller than the electron range. This is due to the low variation of $\Delta K$ with depth and due to the high integration depth. If $n_{\mathrm{A}}(z)$ were to have only a smooth variation with $z$, the two terms would be approximately equal in magnitude, which can easily be estimated from Figure 1. This very general description of the dependence of emitted X-ray intensities on the sputter depth and the concentration depth profiles 


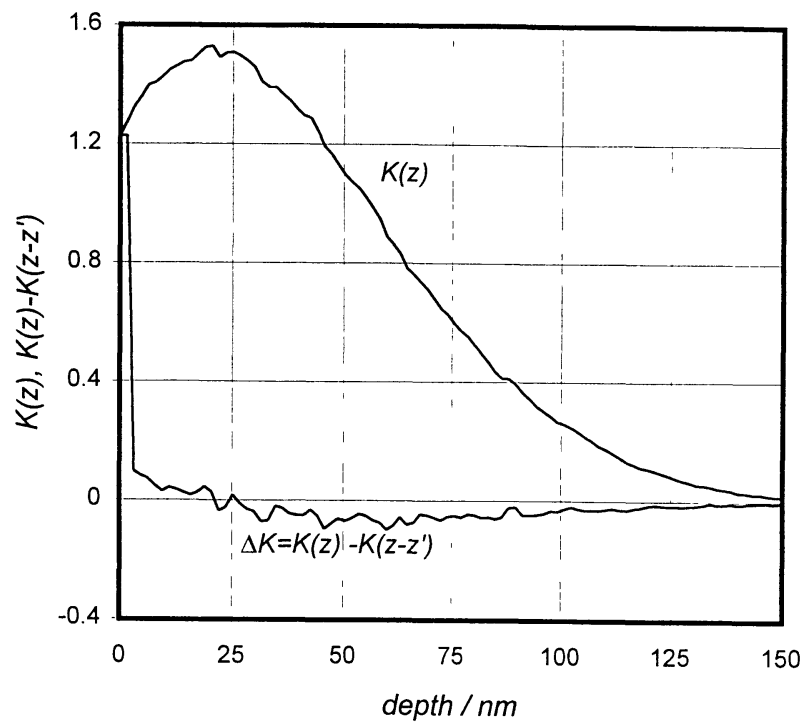

Fig. 1. - MC-calculated depth distribution of emitted $\mathrm{O} K \alpha$ intensity $(K(z))$ and difference $\Delta K$ between two depth distributions shifted in depth by a sputter interval of $2.6 \mathrm{~nm}$. Electron energy is $3 \mathrm{keV}$. Material: Ti-Al-oxide.

is valid for both experimental techniques described above, the sputter-depth profiling as well as the crater edge linescan profiling. But in both techniques, the depth $z^{\prime}$ is besides the elemental concentrations an additional unknown quantity. In analogy to AES-depth profiling $z^{\prime}$ could be determined separately by profiling techniques but it would be a big step forward, if also the real depth could be deduced from the X-ray intensity measurements in one run together with the composition.

2.2 A Quantitation Technique for EPMA-SDP. - Up to now there has existed no closed solution for calculating a free depth profile $n_{\mathrm{A}}(z)$ without making any assumptions concerning the shape of the profile. Attempts succeeded only for certain profiles which could be approximated by a distribution function with a limited number of parameters. As an example this was proposed for the EPMA of ion implantation depth profiles by Ammann and Karduck [11] who described the profiles by Gaussian distributions. Such an approximation is not suitable for the present problem.

Therefore, following the principles described above the depth profiles of elements in surface near structures must be reconstructed from $k$-ratio line scans across a wedge of a sputter crater by the following technique:

The total depth investigated, i.e. the depth of the crater, is regarded as being divided into very thin fictitious sublayers. The composition of each sublayer is assumed to be constant over its particular depth. A formal division of the total depth into sublayers is made by cutting the $k$-ratio curves into 10 sections, in which the average of all measurements from the crater bottom represents as a first set the composition of the substrate. The 10th set of $k$-ratios results from averaging all data points measured on the intact, non sputtered surface. The $k$-ratio curve in-between is subdivided into 8 sets of averaged $k$-ratios. The reconstruction technique is based on an EPMA thin-film quantitation method using a Monte Carlo model for the calculation of the X-ray depth distributions $[13,15]$. The proposed procedure is illustrated in Figure 2: the evaluation is started with the determination of the bulk composition of the substrate from the first $k$-ratio set by a 


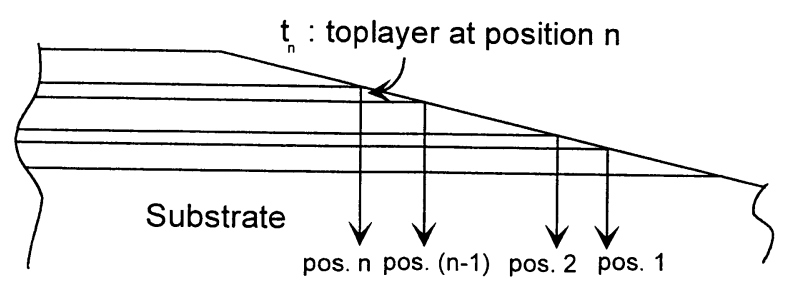

Fig. 2. - Illustration of the reconstruction procedure to calculate quantitative depth profiles from calibrated X-ray intensities ( $k$-ratios).

conventional matrix correction procedure. The second set of $k$-ratios measured at position 1 in Figure 2 can be evaluated by established thin film techniques and gives the composition and coverage of the first sublayer situated on top of the substrate. The formerly calculated composition of the substrate is kept constant and only composition and mass coverage of the sublayer in question are determined. The results obtained so far are fixed and stored for the further steps. In the $n$th step of the evaluation only the $k$-ratio difference $k_{n}-k_{n-1}$ contributes to the determination of coverage and composition of the $n$th sublayer, the structure below is always kept fixed in this quantitative evaluation. In an iteration procedure only the layer parameters of the particular layer are varied as long as calculated $k$-ratios are in best possible agreement with the measured $k$-ratios. As criterion for convergence the minimization of the root mean square value (RMS) between measured and calculated $k$-ratios is used.

As a result the coverage of element $\mathrm{A}$ in the $n$th sublayer can be calculated from the intensity ratio $k_{n}$ as follows:

$$
k_{n} \approx \frac{\text { const }}{I_{\mathrm{s}}} \cdot\left\{n_{\mathrm{A}}\left(z_{n}\right) \cdot \mathrm{d} z_{n} \cdot K(\Gamma, 0)+\int_{z_{n}+\mathrm{d} z_{n}}^{\infty} \mathrm{d} z \cdot n_{\mathrm{A}}(z) \cdot K\left(\Gamma, z-z_{n}\right)\right\}
$$

In this equation we assume the depth increment $\mathrm{d} z_{n}$ to be very thin compared to the electron range at the chosen beam energy.

The integral represents the intensity emitted from the structure below the sublayer of interest. This integral can be calculated numerically from the evaluation results obtained in the steps 1 to $n-1$. If we abbreviate it by $I_{z_{n}}^{\infty}$ we can write the coverage of element $\mathrm{A}$ in the $n$th sublayer as

$$
n_{\mathrm{A}}\left(z_{n}\right) \cdot \mathrm{d} z_{n}=\frac{1}{\text { const } \cdot K(\Gamma, 0)}\left\{k_{n} \cdot I_{\mathrm{s}}-I_{z_{n}}^{\infty}\right\}
$$

with $I_{\mathrm{s}}$ being the intensity of the standard.

For an evaluation $I_{\mathrm{s}}$ and $I_{z_{n}}^{\infty}$ are calculated by a Monte Carlo simulation [16]. This procedure provides full quantification of both, the coverage of the sublayer and the composition. Finally the depth of the sublayer can be calculated by simple summation of the determined thicknesses of all layers above the one in question. $A$ priori information about the shape of the crater is not required for the evaluation. The partition of the total depth investigated into a limited number of fictitious sublayers sets a limiting factor to the depth resolution of the technique. In the present case we have also neglected the dependence of the kernel $K$ on the composition of the structure, i.e. the influence of $n(z)$ on $\Phi\left(z-z^{\prime}\right)$. But this is tenable because in the present structure the changes in composition do not lead to significant changes of $\Phi$. 


\section{Experimental}

The $\mathrm{Ti}_{1-x} \mathrm{Al}_{x} \mathrm{~N}$ films were deposited on high-speed-steel substrates (S6-5-2) using a HV single cathode reactive dc-magnetron (type PK75) sputtering ion plating system (type Z400, Leybold AG). The following experimental conditions were chosen: dc-power: $400 \mathrm{~W}$ corresponding $6 \mathrm{~W} \mathrm{~cm}{ }^{-2}$; bias: $-60 \mathrm{~V}$; substrate temperature: $400{ }^{\circ} \mathrm{C}$; Ar-pressure: $1.2 \times 10^{-2}$ mbar; $\mathrm{N}_{2}$ pressure: $0.84 \times 10^{-3}$ mbar using the 75/25-target $\left(\mathrm{Ti}_{0.74} \mathrm{Al}_{0.26} \mathrm{~N}\right), 1.08 \times 10^{-3}$ mbar using the 50/50target $\left(\mathrm{Ti}_{0.46} \mathrm{Al}_{0.54} \mathrm{~N}\right)$ and 25/75-target $\left(\mathrm{Ti}_{0.25} \mathrm{Al}_{0.75} \mathrm{~N}\right)$. Composition of the compound-targets in atomic ratio $\mathrm{Ti} / \mathrm{Al}$.

Oxidation of the $\mathrm{Ti}_{1-x} \mathrm{Al}_{x} \mathrm{~N}$ films was carried out in a horizontal SiC-tube furnace (Hartung) by flowing synthetic air at a temperature of $770{ }^{\circ} \mathrm{C}$ for a time of $1 \mathrm{~h}$. The flowrate was $2000 \mathrm{sccm}$, and the pressure inside the furnace slightly above $1 \mathrm{~atm}$. The temperature of the samples was measured by a Ni/CrNi thermocouple attached to the silica sliding carriage which enabled a quick transfer of the sample into and out of the furnace.

3.1 EPMA Crater Edge Profiling. - EPMA measurements were carried out with a Camebax SX50 microprobe analyser equipped with 4 wavelength dispersive spectrometers. The measuring conditions applied throughout the present study were:

Primary electron energy: $2.5 \mathrm{keV}, 5 \mathrm{keV}$ and $10 \mathrm{keV}$; beam current: $120 \mathrm{nA}$; counting time: 20 s. For analyses in this low voltage regime we used $\mathrm{O} \mathrm{K} \alpha, \mathrm{N} \mathrm{K} \alpha, \mathrm{Ti} \mathrm{L} \alpha$ and $\mathrm{Al} \mathrm{K} \alpha$-lines. As spectrometer crystal for the analysis of $\mathrm{N}$ and $\mathrm{O}$ a synthetic multilayer of W/Si/W/Si.... with $2 \mathrm{~d}$ spacing of $6.18 \mathrm{~nm}$ was used. For the measurements across the sputter crater the electron beam was defocussed to $10 \mu \mathrm{m}$ to compensate for local inhomogeneities in the element distribution and for effects from selective sputtering. The X-ray signals were calibrated by measurement on the following standards under constant conditions: pure freshly polished aluminium for $\mathrm{Al} \mathrm{K} \alpha$, TiN or $\mathrm{Fe}_{4} \mathrm{~N}$ for $\mathrm{N} \mathrm{K} \alpha$, Ti or TiN for Ti $\mathrm{L} \alpha$, and an electrically conductive $\mathrm{BaFe}_{12} \mathrm{O}_{19}$ for $\mathrm{O}$ $\mathrm{K} \alpha$. The problem of the $\mathrm{Ti} \mathrm{Ll}$ overlap with $\mathrm{N} \mathrm{K} \alpha$ was corrected by a procedure offered in the Camebax software, in which the overlapping $\mathrm{Ti} \mathrm{Ll}$ signal is recalculated from a measurement on a Ti-standard like pure $\mathrm{Ti}$ or $\mathrm{TiC}$ and subtracted from the sum signal measured on the unknown sample. Matrix effects are considered in this correction. The intensity ratios $k_{\mathrm{i}}$ for all elements, i.e. the data base for the data reduction in the EPMA sputter depth profiling, were measured across the wedge of a very flat sputter crater by a conventional step scan. It started at the intact surface of the sample and ended at the bottom of the crater where the oxide layers were completely removed from the hard coating. The measurements at the bottom of the craters can be regarded as representing the bulk composition of the hard coating and could be quantified by conventional matrix correction procedures. Since the wedges were extremely flat the linescans ranged over about $3 \mathrm{~mm}$. Thus the beam diameter of $10 \mu \mathrm{m}$ did not limit the final depth resolution of the technique.

The composition of the hard coatings before oxidation was determined by a thin film EPMA technique according to Ammann and Karduck [16] based on Monte Carlo simulation. This was chosen to differentiate between the oxygen fraction incorporated in the hard coating and a contribution from possible thin oxide layers at the surface.

3.2 AES Crater Edge Profiling. - Additionally AES crater edge line-scan profiling was carried out to determine the composition of the oxidic scale with depth formed on the $\operatorname{Ti}_{0.46} \mathrm{Al}_{0.54} \mathrm{~N}$ film using a Cameca Nanoscan 50 Auger microprobe. The microprobe was equipped with a low energy electrostatically focused field emission electron gun, a semi imaging energy analyzer (type MAC3) working in the direct mode, a X-ray source and an $\mathrm{Ar}^{+}$ion beam gun. 


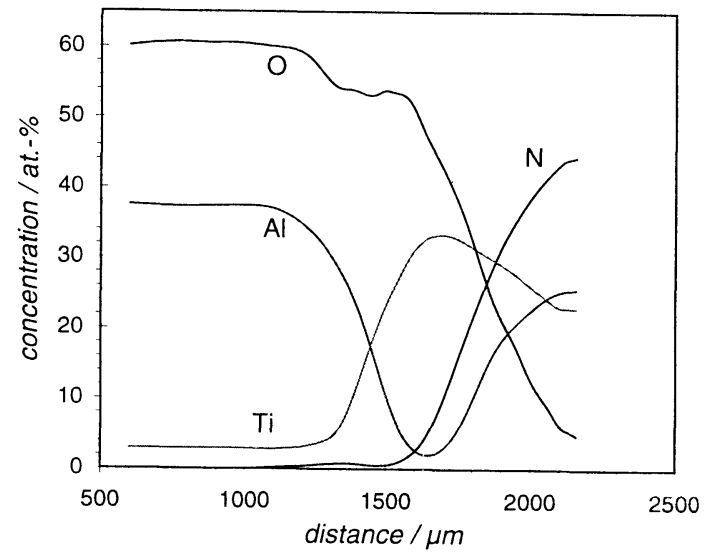

a)

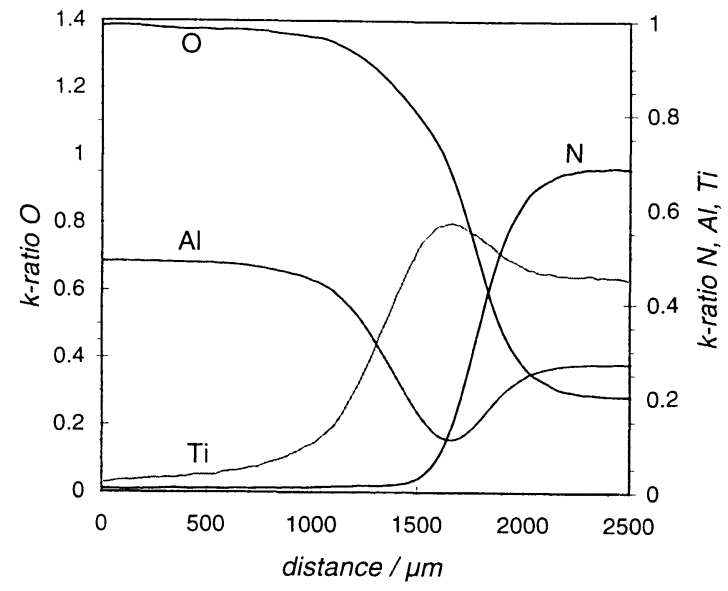

b)

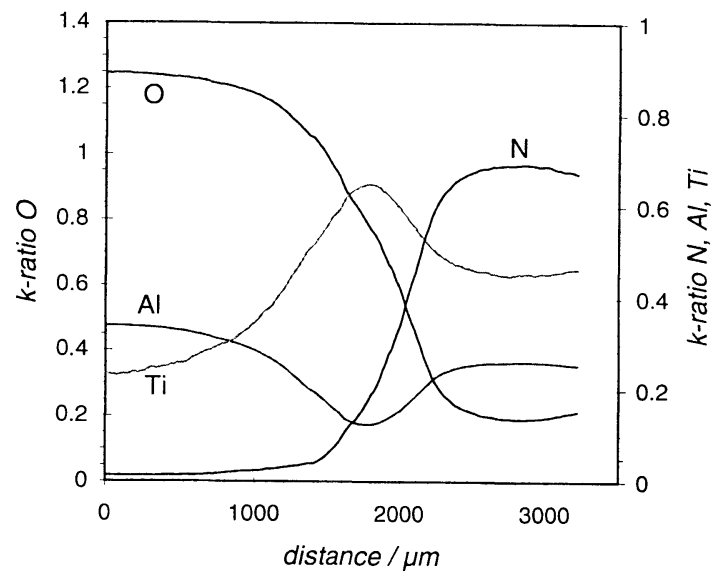

c)

Fig. 3. - Results from crater-edge linescans at oxidized $\mathrm{Ti}_{0.46} \mathrm{Al}_{0.54} \mathrm{~N}$, plotted versus the real distance along the line: a) Quantified AES linescan. b) EPMA-linescan of $k$-ratios measured with $2.5 \mathrm{keV}$. c) EPMAlinescan of $\dot{k}$-ratios measured with $5.0 \mathrm{keV}$.

With a defocussed ion beam operating at an incidence angle of $33^{\circ}$ and $5 \mathrm{keV}, 500 \mathrm{nA}$ a crater with a depth of $240 \mathrm{~nm}$ was sputtered through the oxide overlayer formed on the nitride coating. The depth of the crater was determined by microprofilometry using a Dektak IIa (Sloan).

The AES crater edge line-scans were recorded in the $I_{\text {peak }}-I_{\text {background }}$ mode (P-B). The energy of the primary electrons was $5 \mathrm{keV}$, the beam current $52 \mathrm{nA}$ and the beam diameter, characterized by the SEM resolution, was $0.5 \mu \mathrm{m}$. During the line-scan measurements the residual gas pressure of the AES was in the low $10^{-10}$ mbar range.

The (P-B)-intensities of the following Auger lines were considered for the line-scan analysis: $\mathrm{N}-\mathrm{KVV}$; Ti-L ${ }_{3} \mathrm{M}_{23} \mathrm{~V}$; O-KVV and $\mathrm{Al}-\mathrm{KL}_{23} \mathrm{~L}_{23}\left({ }^{1} \mathrm{D}\right)$.

The quantitative analysis of the $\mathrm{N}$ depth distribution could be determined only with low accuracy because both the $N-K_{23} L_{23}$ transition is superimposed with the Ti- $\mathrm{L}_{3} \mathrm{M}_{23} \mathrm{M}_{23}$ transition and 


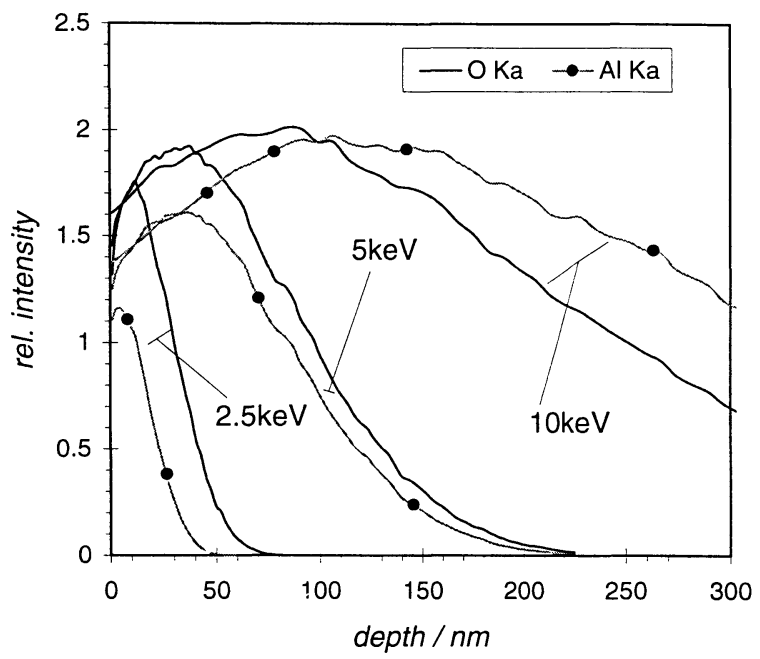

Fig. 4. - Typical X-ray depth distributions of $\mathrm{O} \mathrm{K} \alpha$ and $\mathrm{Al} \mathrm{K} \alpha$ in an Al-Ti-oxide, corrected for absorption.

the peak shape of the Ti lines is modifying with the bond of Ti to $\mathrm{N}$ or $\mathrm{O}$. This last point is the reason that the content of $\mathrm{Ti}$ could be determined only with low precision too. Nevertheless the $\mathrm{Ti}$, $\mathrm{Al}, \mathrm{N}$ and $\mathrm{O}$ depth distributions have been analysed by the following procedure: the overlapped $\mathrm{N}$ - and Ti lines were deconvoluted and the relative sensitivity factors $S_{\mathrm{i}}$ of the components i determined to convert the intensity profiles $I_{\mathrm{i}}(x)$ into concentration profiles $c_{\mathrm{i}}(x)=S_{\mathrm{i}} \times I_{\mathrm{i}}(x)$. This procedure will be published in detail elsewhere.

\section{Results and Discussion}

Figures $3 \mathrm{~b}$ and $3 \mathrm{c}$ give the raw $k$-ratio data obtained from the linescan measurements across the edge of a sputter crater in an oxide-layer structure grown on a $\mathrm{Ti}_{0.46} \mathrm{Al}_{0.54} \mathrm{~N}$ - hard coating. To compare the influence of the excitation depth on the capability to resolve concentration depth profiles, the line-scan measurements were carried out at $2.5 \mathrm{keV}$ and $5 \mathrm{keV}$. At $2.5 \mathrm{keV}$ the EPMA results (Fig. 3b) are in rather good agreement with the corresponding AES-crater edge profiles (Fig. 3a). The left part of the profiles represents the surface of the oxide film which can be identified as an $\mathrm{Al}_{2} \mathrm{O}_{3}$-layer. This layer is followed by a titanium-rich oxide with low aluminium content. Both the AES- and the EPMA profiles do not reveal sharp transition regions and there is no plateau in the concentration profiles in the range of the titanium oxide. The right part of the profiles represent the composition of the crater bottom, i.e. the Ti-Al-nitride. The details of the single curves are nearly identical for both techniques and the transition ranges between the $\mathrm{Al}_{2} \mathrm{O}_{3}$ and the titaniumoxide have the same width in both profiles. The rather good depth resolution of EPMA can be explained by the low excitation depth at $2.5 \mathrm{keV}$. According to Figure 4 the depth distribution of generated $\mathrm{O} \mathrm{K} \alpha$ intensity is very near to the surface. The maximum excitation takes place in a depth of $12 \mathrm{~nm}$ and the X-ray range is $70 \mathrm{~nm}$. With $5 \mathrm{keV}$ these values increase significantly to $38 \mathrm{~nm}$ and $230 \mathrm{~nm}$, respectively. Thus, the near-surface $\mathrm{X}$-ray production at $2.5 \mathrm{keV}$ is responsible for the surprisingly good sensitivity of the EPMA signals to changes in the elements depth distributions. Of course, the information depth of AES with a few nm is smaller than the one of EPMA, but in the particular case of oxide layers on a technical material a possible interface roughness causes smooth transitions from one oxide type to the next, 


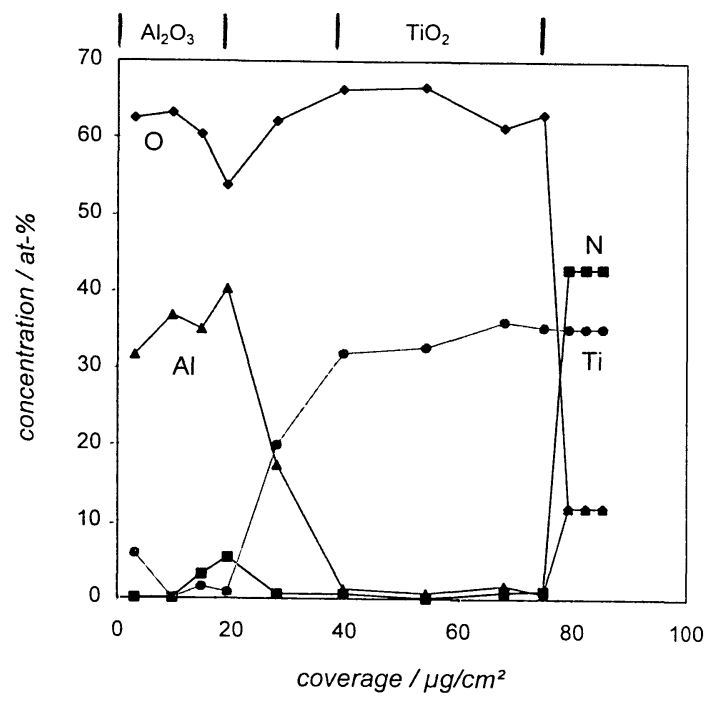

a)

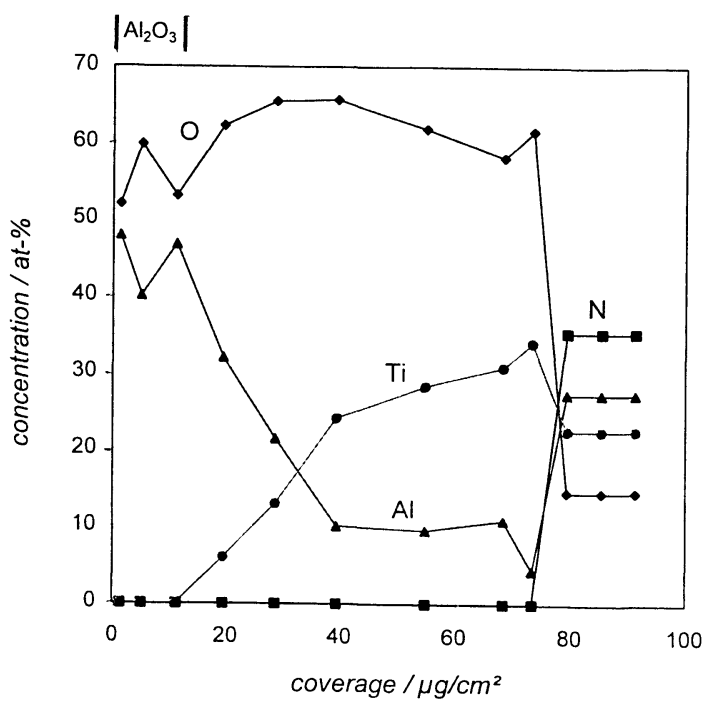

b)

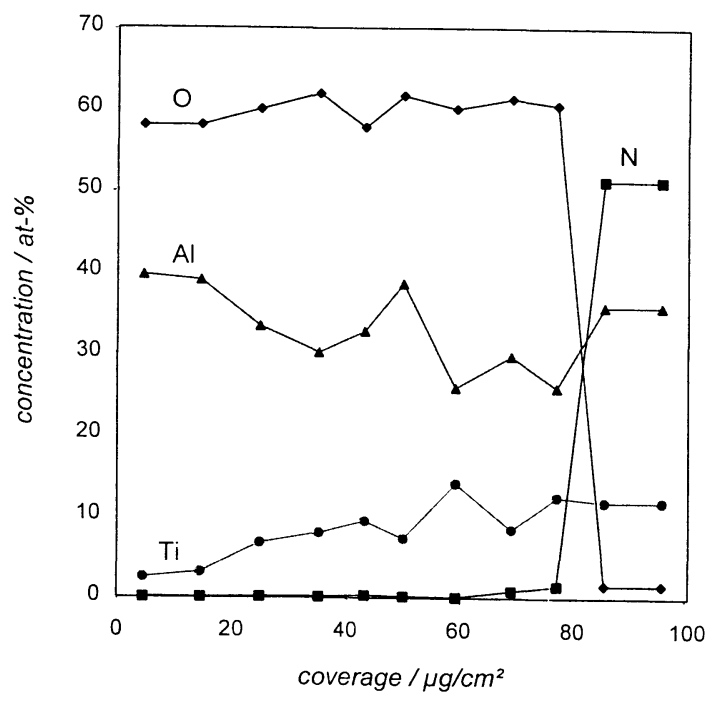

c)

Fig. 5. - Results of a quantitative reconstruction of the depth profiles in oxide scales on $\mathrm{Ti}_{1-x} \mathrm{Al}_{x} \mathrm{~N}$ hard coatings after $1 \mathrm{~h}$ at $770^{\circ} \mathrm{C}$ in air. a) $x=0.26$, b) $x=0.54$, c) $x=0.75$.

so that the structure itself is the limiting factor to depth resolution. The linescan recorded with $5 \mathrm{keV}$ is shown in Figure 3c. Due to the increased depth of excitation, a deterioration of depth resolution is to be noted, causing smoother, less pronounced profiles. But still a variation of the $k$-ratios with the sputter depth is present which can be evaluated in order to obtain quantitative data for the depth distributions.

Although the profiles in Figure $3 \mathrm{~b}$ show a surprisingly good depth resolution, the data are not 


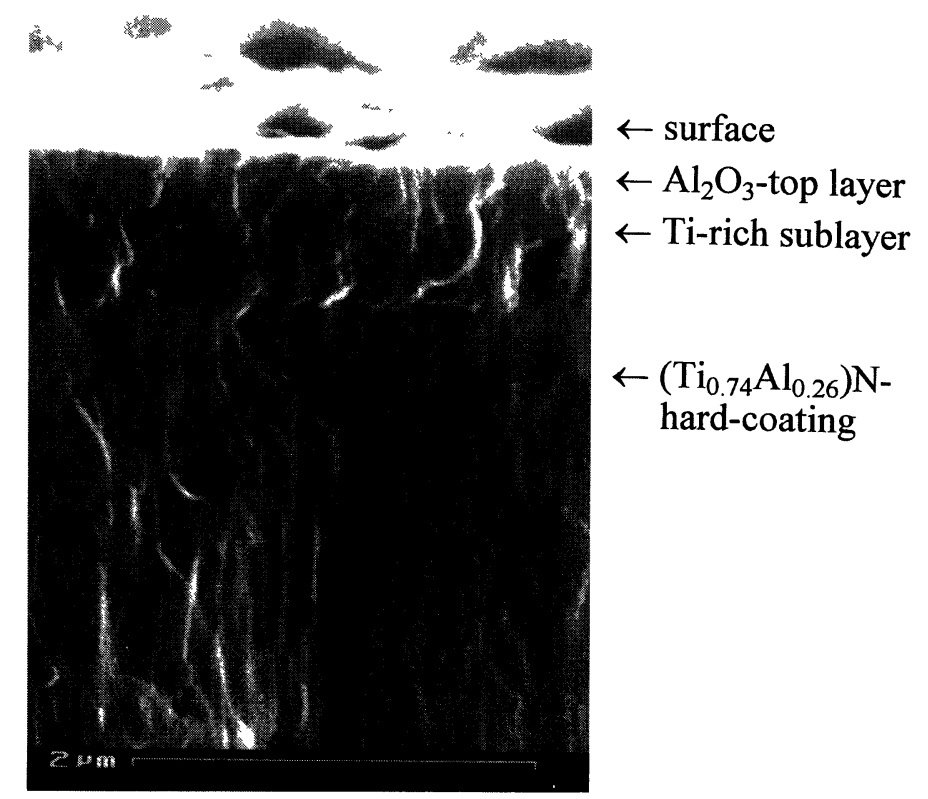

Fig. 6. - SEM image of a fractured layer system of oxidized $\operatorname{Ti}_{0.74} \mathrm{Al}_{0.26} \mathrm{~N}$.

appropriate for further quantitative evaluation by a thin film-technique because the electrons do not penetrate single structural elements with constant composition as the $\mathrm{Al}_{2} \mathrm{O}_{3}$-layer on the top. But, in particular this penetration is required for the calculation of mass thicknesses of the individual sublayers, from which also the compositions are to be deduced. The penetration of single sublayers by the electrons is a basic prerequisite to apply the thin film quantification technique, on which the method described above is based [13].

So far the qualitative or semiquantitative results (AES) shown in Figure 3 give only tentative information about the oxide structure and the composition with depth. A general drawback of both linescanning techniques is that the profiles contain no quantitative, nor even no qualitative or at least linear information about the real depth of each analysis point on the crater edge. Thus, the shape of the crater strongly influences the profiles and therefore distorts most of the depth information.

By applying the quantification technique described above to the $k$-ratio data obtained at $5 \mathrm{keV}$ and $10 \mathrm{keV}$ the depth profiles shown in Figures $5 \mathrm{a}-\mathrm{c}$ could be deduced. The part of the linescans in Figure 3 with slopes $\neq 0$, i.e. the range corresponding to the wedge of the crater, was subdivided into 9 fictitious sublayers giving 9 quantified depth elements. Each depth element was quantified with respect to composition and mass thickness (coverage). Plotting the resulting single element concentrations versus the sum of mass thicknesses down to the depth element in question results in real depth profiles as shown in Figure 5 for three different oxidized hard coatings $\mathrm{Al}_{x} \mathrm{Ti}_{1-x} \mathrm{~N}$, with $x=0.26, x=0.54$ and $x=0.75$. In the first two cases with low or medium Al-content in the hard coating, an aluminium oxide is detected as the top oxide layer. Below this a transition zone appears with decreasing $\mathrm{Al}$-content and increasing Ti-content. The coating with $x=0.26$ shows a transition zone of $20 \mu \mathrm{g} / \mathrm{cm}^{2}$ width $(\sim 65 \mathrm{~nm})$ after which an aluminium-free titanium oxide follows. According to the quantitative values this oxide can be attributed to be of the type $\mathrm{TiO}_{2}$. Additionally this oxide structure shows an indication of small Ti-traces on the surface which were 
confirmed by XPS-analysis. The coating with medium Al-content $x=0.54$ is also covered with an aluminium oxide on top of the scale. Due to the higher aluminium content of this hard coating the depth profile in Figure $5 \mathrm{~b}$ reveals still 10 at.- $\% \mathrm{Al}$ in the titanium-rich oxide and the transition zone between the two oxide types is larger and stretches over $27 \mu \mathrm{g} / \mathrm{cm}^{2}(\sim 90 \mathrm{~nm})$. These transition zones can be explained as regions containing a mixture of both oxide types adjoining this zone which could be designated as a meshed structure. This is demonstrated in Figure 6 by an SEM image of the fractured oxide scale on the hard coating with $x=0.26$. The transition zone is larger the higher the $\mathrm{Al}$-content of the hard coating. The Al-rich coating with $x=0.75$ produced an oxide scale completely composed of a mixture of $\mathrm{Al}$ - and Ti-oxides with a smooth gradient in $\mathrm{Al}$ - and Ti-contents (Fig. 5c). The Ti-content drops from 12-13 at.-\% at the interface between hardcoating and scale down to $1-2$ at. $-\%$ at the surface. A comparison of the three different profiles shown in Figure 5 reveals, that the influence of the original composition of the hard coating is clearly resolved by the new EPMA-technique. The lower the Al-content of the hard coating, the stronger the tendency to form separate pure oxide layers wilh $\mathrm{Al}_{2} \mathrm{O}_{3}$ on top and $\mathrm{TiO}_{2}$ near the substrate. With increasing $\mathrm{Al}$-content of the hard coating the transition region between both pure oxides becomes wider, indicating a meshed structure. For the high Al-content the whole oxide scale consists of a mixture of both oxide types. Thus, contrary to the AES-technique, the new EPMA sputter depth profiling method can provide quantitative depth profile data from the $\mathrm{X}$-ray analysis of complex oxide layers for the concentrations as well as for the depth coordinate. The quantification of the EPMA data works well, although in the present case two of the three elements analysed, $\mathrm{Ti}$ and $\mathrm{Al}$, are also present in the coating below the oxide layer. In contrast, the simplified quantification of the AES-data by using $\mathrm{Al}_{2} \mathrm{O}_{3}$ and the hard coating as a kind of internal standards failed to work out the Al-content of the buried titanium-rich oxide. The information gathered from differences between $k$-ratios measured at different but adjacent depths on the wedge is sufficient for a quantification of the particular depth increment of the layer. The accuracy of the quantification is assumed to be $10 \%$ relative.

\section{Conclusions}

The combination of wavelength-dispersive EPMA with ion-beam sputtering opens up the possibility of quantitative in-depth analysis in the submicron regime. Even in cases of oxide scales on technical materials, where particular elements are present in both the scale and the substrate, the new EPMA-sputter depth profiling is capable of determining real quantitative depth profiles. The composition and the depth in terms of mass coverage can be evaluated in the same run. The depth resolution is up to now restricted by the model which permits the subdivision of the total depth of the structure into 9-16 fictitious sublayers. A prerequisite for successful application of the technique is that the applied primary electron energy is correctly suited to the thickness of the individual sublayers of the structure or in case of gradients to their depth of transition. In any case the range of primary electrons should be slightly larger than these structural features. If it is shorter, it becomes difficult or even impossible to determine the thickness of single sublayers correctly. If the range is chosen to be very large compared to the total thickness of the structure, the technique becomes rather insensitive for the compositional changes with depth. Thus, a sufficient degree of experience in EPMA-thin film analysis is required to chose the right parameters.

The accuracy attained in the quantitative evaluation up to now can be estimated from the present results to be better than $10 \%$. The results presented are an encouragement to carry on the development of this technique by implementing an ion gun into a X-ray microprobe analyser. This would enable real sputter depth profiles to be acquired in-situ on one particular point of a surface maintaining lateral resolution. But most important, it would avoid undesired oxidation of the freshly sputtered surface during transport of the sample. 


\section{Acknowledgements}

This report includes work carried out by N. Ammann, A. Barth and R. Cremer. The assistance of personnel is gratefully acknowledged.

\section{References}

[1] Baumgartl S., Ryder P.L. and Bühler H.E., The detectability limits of thin coatings measured with the electron microprobe, Z. Metallk. 64(1973) 655.

[2] Brown. J.D., Analysis of thin films by electron Probe microanalysis, in Microbeam Analysis, D.E. Newbury Ed. (San Francisco Press, San Francisco, 1988) pp. 271-272.

[3] Ammann N., Lubig A. and Karduck P., Quantitative Analysis of $\left(\mathrm{Y}_{2} \mathrm{O}_{3}\right)_{X}\left(\mathrm{ZrO}_{2}\right)_{1-X}$ Films on Silicon by EPMA, Mikrochim. Acta [Suppl.] 12 (1992) 213-219.

[4] Pouchou J.L. and Pichoir F., A new model for quantitative X-ray microanalysis, Part II: Application to in depth analysis of heterogeneous samples, La recherche aérospatiale, no 5 (1984) 47.

[5] Hunger H.J., Baumann W. and Schulze S., A New Method for Determining the Thickness and Composition of Thin Layers by Electron Probe Microanalysis, Cryst. Res. Technol. 20 (1985) 1427-1433.

[6] Waldo R.A., An iteration procedure to calculate film compositions and thicknesses in electron-probe microanalysis, in Microbeam Analysis, D.E. Newbury Ed. (San Francisco Press, San Francisco, 1988) pp. 310-314.

[7] Bastin G.F., Heijligers H.J.M. and Dijkstra J.M., Computer programs for the calculation of X-ray intensities emitted by elements in multilayer structures, in Microbeam Analysis, J.R. Michael and P. Ingram Eds. (San Francisco Press, San Francisco, 1990) pp. 159-160.

[8] Pouchou J.L. and Pichoir F., Quantitative analysis of homogeneous and stratified microvolumes applying the model PAP, in Electron Probe Quantitation, K.F.J. Heinrich and D.E. Newbury Eds. (Plenum Press, New York, 1991) pp. 31-75.

[9] Ammann N., Gleitsmann G., Heuken M., Heime K. and Karduck P., Investigation of Implanted Gallium Depth Distributions in $\mathrm{ZnS}_{X} \mathrm{Se}_{1-X}$ by EPMA, Mikrochim. Acta 114/115 (1994) 165-173.

[10] Bastin G.F., Dijkstra J.M., Heijliger H.J.M. and Klepper D., Quantitative Electron Probe Microanalysis of Multi-layer Structures, Mikrochim. Acta [Suppl.] 12 (1992) 93-97.

[11] Ammann N. and Karduck P., Quantitative depth profile Analysis by EPMA combined with Monte-Carlo simulation, Surf. and Interface Anal. 22 (1994) 54 -59.

[12] D. Briggs and M.P. Seah Eds., Practical surface analysis, 2nd ed. (John Wiley Sons, Chichester, 1990).

[13] von Richthofen A., Matsuo M., Karduck P. and Ammann N., Combined EPMA and AES depth profiling of a multilayer Ti-Al-O-N coating, Mikrochim. Acta 114/115 (1994) 511-523.

[14] Karduck P. and von Richthofen A., EPMA sputter depth profiling: a new technique for quantitative indepth analysis of layered structures, in Proceedings of the 29th Annual Conference of the Microbeam Analysis Society, E.S. Etz Ed. (VCH Publishers, 1995) pp. 205-206.

[15] Ammann N., Quantitative Tiefenprofilanalyse mit der Elektronenstrahlmikrosonde - Entwicklung der Technik und Untersuchungen zur Diffusion von Gallium in $\mathrm{ZnSe} / \mathrm{GaAs}$, Fortschr.-Ber. VDI Reihe 8, Nr. 399 (VDI-Verlag, Düsseldorf, 1994).

[16] Ammann N. and Karduck P., A further developed Monte Carlo model for the quantitative EPMA of complex samples, in Microbeam Analysis, J.R. Michael and P. Ingram Eds. (San Francisco Press, San Francisco, 1990) pp. 150-154. 